\section{Loyalitas Kreativitas \\ Aldi Masyarakat Kreatif}

P-ISSN 2722-2101, E-ISSN 2722-4201

Program Studi Ekonomi Manajemen Universitas Pamulang

Jurnal LOKABMAS Kreatif Vol.01,No.02 Juli 2020, Hal. 1-4

Email:jurnalkreatif.manajemen@gmail.com

\title{
MEMBANGUN JIWA KEWIRAUSAHAAN DAN STRATEGI BISNIS SKALA UMKM BAGI PEMULA
}

\author{
Tubagus Arya Abdurachman, Nani Mulyani, Erick Agustinus, \\ Syaibatul Hamdy, RA. Kadarmanta.
}

Dosen Ekonomi Fakultas Ekonomi Akutansi Universitas Pamulang

Email_dosen01872@unpam.ac.id, dosen01981@unpam.ac.id, agustinusrick@gmail.com, syaibatul.hamdy56@gmail.com, a.kadarmanta61@gmail.com

\begin{abstract}
ABSTRAK
Tujuan dari Kegiatan Pengabdian Kepada Masyarakat adalah untuk melaksanakan salah satu Tri Dharma Perguruan Tinggi. Selain itu diharapkan dengan pengabdian kepada masyarakat tersebut keberadaan perguruan tinggi dapat memberikan kontribusi besar kepada pengembangan dan penerapan keilmuan kepada masyarakat.

Metode pelaksanaan pengabdian ini dilakukan dalam beberapa kegiatan yaitu tahap survei yaitu sosialisasi dilakukan dengan menyusun berbagai hal yang akan disampaikan pada saat kegiatan pengabdian yang akan dilakukan yang meliputi: penyusunan materi yang akan diberikan, penyusunan jadwal pemberian materi, pembagian tugas tim pengabdian dan survei ke lokasi pengabdian. Tahap sosialisasi yaitu sebelum kegiatan pengabdian dilaksanakan terlebih dahulu dilakukan tahap sosialisasi yaitu melakukan silaturahmi dengan kepala sekolah, menyampaikan maksud dan tujuan pengabdian ini. Pada tahap ini juga dilakukan jalinan kerjasama dan menentukan jadwal kegiatan pengabdian. Tim pelaksana kegiatan pengabdian pada masyarakat adalah dosen Fakultas Ekonomi jurusan Akutansi sebanyak 5 orang. Tim pengabdian memberikan materi tentang Pelatihan Membangun Jiwa Kewirausahaan Dan Stategi Bisnis Skala UKM Bagi Pemula, diKelurahan Sawah baru.

Hasil pengabdian masyarakat yang diperoleh adalah bertambahnya keilmuan bagi Para Peserta Ukm Pemula Dikelurahan Sawah Baru agar mereka memiliki keterampilan tambahan dalam memanfaatkan limbah kain perca sehingga mereka memiliki bekal tambahan untuk menghasilkan pendapatan sendiri. Ilmu yang diperoleh pada Pengabdian Masyarakat kali ini diharapkan mampu memberikan semangat baru bagi kita dalam menyampaikan materi dan motivasi serta berkontribusi bagi generasi muda, baik dilingkungan sekolah, kampus dan keluarga.
\end{abstract}

\section{Kata Kunci: Jiwa Kewirausahaan, Stategi Bisnis,Ukm}

\begin{abstract}
ABSTRAC
The purpose of Community Service Activities is to carry out one of the Higher Education Tri Dharma. In addition, it is expected that through community service, the existence of higher education institutions can make a major contribution to the development and application of knowledge to the community. The method of implementing this service is carried out in a number of activities, namely the survey stage, namely the socialization carried out by arranging various things to be delivered at the time of service activities that will be carried out which include: preparation of material to be given, preparation of material delivery schedule, division of tasks of the service team and survey to the location devotion. The socialization phase is before the community service activities are carried out first, the socialization phase is to make a friendship with the school principal, conveying the aims and objectives of this service. At this stage cooperation is also carried out and determine the schedule of service activities. The implementing team of community service activities is a lecturer of the Faculty of Economics majoring in Accounting as many as 5 people. The dedication team provided material on the Training
\end{abstract}




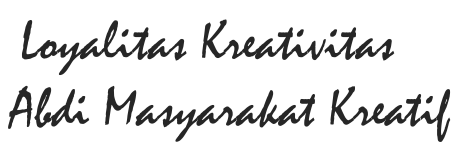

P-ISSN 2722-2101, E-ISSN 2722-4201

Program Studi Ekonomi Manajemen Universitas Pamulang

Jurnal LOKABMAS Kreatif Vol.01,No.02 Juli 2020, Hal. 1-4

Email:jurnalkreatif.manajemen@gmail.com

to Build Entrepreneurial Souls and SME Scale Business Strategy for Beginners, in the new Sawah Village.

The result of community service is the increase of knowledge for the SME Beginner Participants in Sawah Baru Village so that they have additional skills in utilizing patchwork waste so that they have additional provisions to generate their own income. The knowledge gained at Community Service this time is expected to be able to provide new enthusiasm for us in conveying material and motivation as well as contributing to the younger generation, both within the school, campus and family environments.

\section{Keywords: Entrepreneurial Soul, Business Strategy, Ukm}

\section{PENDAHULUAN}

Di era globalisasi ini, memperoleh pekerjaan bukanlah hal yang mudah karena semakin ketatnya persaingan di dunia kerja. Para pencari kerja bukan hanya bersaingan dengan sesama pencari kerja dalam negeri, tetapi juga bersaingan dengan tenaga kerja dari mancanegara.

Pada bulan Februari 2018, BPS melaporkan bahwa jumlah pengangguran di Indonesia sebanyak 6,87 juta jiwa. Sebaran Jumlah Pengangguran di Indonesia Kepala BPS, Suhariyanto, menyebutkan bahwa Tingkat Pengangguran Terbuka terbanyak berada di Jawa Barat, yang berada di angka $8,16 \%$. Di posisi kedua dan ketiga ada Banten di angka 7,72\% dan Maluku di angka 7,38\%. Persentase pengangguran paling rendah berada di Bali dengan 0,86\%, Sulawesi Barat dengan $2,45 \%$, dan Bengkulu dengan 2,70\%. Sedangkan jika dilihat dari tingkat pendidikan, lulusan Sekolah Menengah Kejuruan atau SMK menyumbang porsi pengangguran terbanyak, yaitu sebesar $8,92 \%$.

Masih tingginya tingkat pengangguran di Indonesia, memicu lahirnya UMKM (Usaha Mikro Kecil Menengah) sebagai salah satu solusi mengurangi pengangguran. UMKM merupakan salah satu roda penggerak perekonomian Indonesia. Menurut Kementerian Koperasi dan UKM, sumbangan UMKM terhadap PDB Indonesia mencapai angka 60,34 persen pada tahun 2017. Artinya sekitar 60 persen nilai barang dan jasa yang diproduksi di Indonesia pada tahun 2017 berasal dari sektor UMKM.

Salah satu jenis UMKM yang menjanjikan di masa depan adalah bisnis fashion. Usaha dibidang fashion sepertinya masih menjadi primadona di Indonesia, terutama yang dilakukan secara online. Menurut The Jakarta Post, produk fashion menjadi salah satu incaran favorit orang Indonesia ketika berbelanja online. Lingkup industri fashion sendiri sangat luas, dari baju, celana, rok, jilbab, tas, sepatu hingga aksesoris.

Bisnis di bidang fashion ini, selain menguntungkan juga memiliki peluang yang sangat luas. Karena itu, kompetisi di bisnis ini juga cukup ketat. Hal yang harus dilakukan oleh pebisnis fashion adalah selalu mengikuti tren yang sedang diminati pasar. Pebisnis fashion harus pandai membaca keinginan dan kebutuhan pasar.

Pada dasarnya, banyak sekali bahan yang bisa digunakan sebagai bahan baku bisnis ini. Pada kesempatan ini, Bisnis ini membutuhkan modal yang tidak terlalu besar, karena itu cocok untuk orang yang baru mulai mencoba berkecimpung di dunia bisnis.

\section{RUMUSAN MASALAH}

Dengan mempertimbangkan latar belakang yang telah dijelaskan diatas kami berinisiatif untuk membentuk pengabdian masyarakat bagi Pelatihan Membangun Jiwa Kewirausahaan Dan Stategi Bisnis Skala UKM Bagi Pemula, diKelurahan Sawah baru. khususnya dalam program pelatihan agar para UKM memiliki keterampilan dalam Pelatihan Membangun Jiwa Kewirausahaan Dan Stategi Bisnis Skala UKM Bagi Pemula, diKelurahan Sawah baru..

\section{TUJUAN PELAKSANAAN}

1. Memberikan pengetahuan kepada Ukm pemula dikelurahan Sawah baru mengenai 
peluang usaha yang bisa dimanfaatkan untuk menambah penghasilan.

2. Memberikan pengetahuan kepada ukm pemula dikelurah sawah baru mengenai Pelatihan Membangun Jiwa Kewirausahaan Dan Stategi Bisnis Skala UKM Bagi Pemula, diKelurahan Sawah baru..

\section{TINJAUAN PUSTAKA}

Menurut Sicilia Sawitri, dkk (2010:406) industri garmen merupakan industri yang mengolah sebuah produk yang berasal dari penggabungan dan penjahitan berbagai potongan dan komponen hingga menjadi suatu bentuk jadi berupa busana. Sedangkan kain perca merupakan limbah garmen yang berupa sisa potongan pada proses pengguntingan kain, baik pada pembuatan pakaian yang dilakukan oleh ibu rumah tangga, industri kecil, maupun industri besar.

Pada dasarnya semua orang memiliki potensi untuk menjalankan bisnis sesuai dengan minat dan latar belakang masing - masing, baik pendidikan, keluarga maupun pengalaman kerja yang telah dimiliki. Kewirausahaan merupakan petualang, pengambil risiko, kontraktor,pengusaha (orang yang mengusahakan sesuatu pekerjaan tertentu, danpencipta yang menjual hasil hasil ciptaannya (Hendro, 2011: 29).Sedangkan menurut Prof.L.R.Dicksee (2017) bisnis adalah suatu bentuk aktivitas yang utamanya bertujuan untuk memperoleh keuntungan bagi yang mengusahakan atau yang berkepentingan dalam terjadinya aktivitas tersebut.Kata "bisnis"diambil dari bahasa Inggris "bussines" yang secara umum berarti suatu aktivitas jual beli baik barang ataupun jasa untuk mendapatkan laba. Menurut Ibrahim Jones dan Sewu LindawatyBisnis (2007: 25) merupakan salah satu aktivitas usaha yang utama dalam menunjang perkembangan ekonomidiproses lagi untuk menghasilkan kerajinan tangan.

\section{HASIL DAN PEMBAHASAN}

Kegiatan Pengabdian Masyarakat Universitas Pamulang yang dilakukan oleh dosen-dosen program studi Manajemen Akutansi telah berjalan dengan lancar dan mendapat sambutan hangat dari tempat pelaksanaan kegiatan ini yaitu di Aula Kelurahan Sawah Baru .

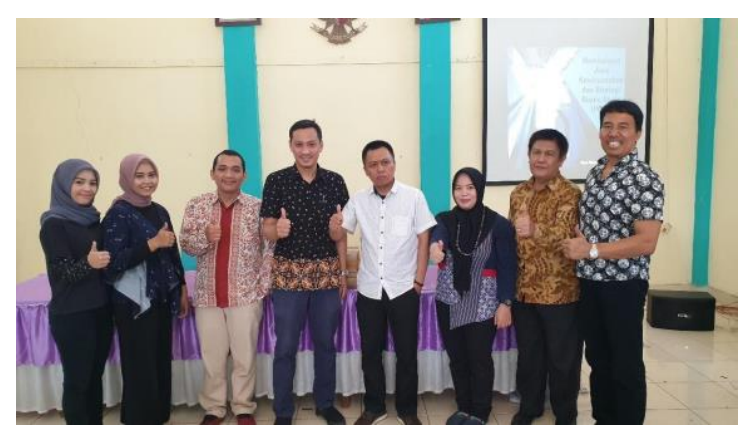

Harapan kami dengan pengabdian ini adalah meningkatnya pengetahuan dan keterampilan UKMdalam membuat hiasan pakaian dan tas dengan memanfaatkan limbah kain perca dan meningkatnya jiwa enterpreuneur para UKM sehinga mereka tertarik untuk memanfaatkan kain perca sebagai peluang usaha.

\section{KESIMPULAN DAN SARAN \\ Kesimpulan}

Pengetahuan dan pemahaman Ukm Pemula Dikelurahan Sawah Baru tentang Pelatihan Membangun Jiwa Kewirausahaan Dan Stategi Bisnis Skala UKM Bagi Pemula, diKelurahan Sawah baru.. Dan semakin meningkatnya jiwa enterpreuneur para ukm sehingga menimbulkan minat untuk berwirausaha.

\section{Saran}

Mengadakan sosialisasi dan pelatihan serupa pada UKM lain di Kecamatan yang lain, dengan materi yang serupa. Adanya kesinambungan program pasca kegiatan pengabdian ini sehingga UKM benar-benar dapat mengembangkan kemampuannya dalam berkreasi. Diadakannya kegiatan yang berkaitan dengan pemasaran produk yang sudah dihasilkan.

\section{DAFTAR PUSTAKA}

Muljono, Ryan Kristo. 2018. Digital Marketing Concept. Gramedia Pustaka Utama. Jakarta. 


\section{Loyalitas Kreativitas \\ Aldi Masyarakat Kreatif}

P-ISSN 2722-2101, E-ISSN 2722-4201

Program Studi Ekonomi Manajemen Universitas Pamulang Jurnal LOKABMAS Kreatif Vol.01,No.02 Juli 2020, Hal. 1-4 Email:jurnalkreatif.manajemen@gmail.com
Pasaribu, V. L. D., Agrasadya, A., Shabrina, N., \& Krisnaldy, K. (2020). MENJADI ENTERPRENEUR MUDA YANG MEMILIKI JIWA LEADERSHIP UNTUK MENGHADAPI MASA DEPAN. Abdi Laksana, 1(1)

Pasaribu, V. L. D., Elburdah, R. P., Sudarso, E., \& Fauziah, G. (2020). PENGGUNAAN MANAJEMEN WAKTU TERHADAP PENINGKATAN PRESTASI BELAJAR DI SMP ARAISIYAH. Jurnal ABDIMAS, 1(1)

Pasaribu, V. L. D., Susanti, F., \& Hartuti, E. T. K. (2019). MEMOTIVASI SISWA DAN SISWI SMK LETRIS INDONESIA DI DALAM MENENTUKAN PILIHAN UNTUK MELANJUTKAN PENDIDIKAN ATAU BEKERJA SETELAH LULUS SEKOLAH. Jurnal Pengabdian Dharma Laksana, 1(2), 161-172.

Pasaribu, V. L. D., Oktrima, B., Prabowo, B., Arianto, N., \& Haryoko, U. B. (2020). PROGAM PENDAMPINGAN DAN PENYELENGGARAAN PENDIDIKAN ANAK PADA USIA DINI TERHADAP PRESTASI BELAJAR DILINGKUNGAN RT 020 RW 009. KEL GIRI PENI. KEC WATES. YOGYAKARTA. JURNAL LOKABMAS KREATIF, 1(1), 71-75.

Pasaribu, V. L. D., Sulaiman, S., Sutiman, S., Thaharudin, T., \& Purnomo, B. Y. (2020). PENGENALAN LETAK POSYANDU TERDEKAT DIKELURAHAN PISANGAN DENGAN MANAJEMEN PEMASARAN REVOLUSI 4.0 UNTUK MENINGKATKAN PENGETAHUAN MASYARAKAT LETAK DAN FUNGSI POSYANDU TERDEKAT PADA KELURAHAN PISANGAN. DEDIKASI PKM, 1(1), 105-110

Pasaribu, V. L. D., \& Krisnaldy, K. (2019). Manajemen Risiko dan Asuransi.

Paluzi, Hanna. 2016. Kreasi Perca (Buku Kreasi Anak). Indiva Media Kreasi. Surakarta.

Tripratiwi, Agni. 2015. Desain Flanel dan Perca. Tiara Aksa. Surabaya. https://www.jurnal.id/id/blog/4-jenis-strategipemasaran-produk-yang-perlu-anda-ketahui/

https://databermanfaat.blogspot.com/2014/06/ berbagi-makalah-bertemakan-kain-perca.html

https://bisnisukm.com/memanfaatkan-kainperca-sebagai-peluang-usaha.html https://olympics30.com/kerajinan-darikain-perca/

https://ilmuseni.com/seni-rupa/kerajinantangan/macam-macam-kerajinan-tangan-darikain-perca

https://www.berbagaireviews.com/2018/08/ker ajinan-kain-perca-bahan-kain-perca.html?m=1

https://santaidamai.com/kerajinan-dari-kainperca/

http://repositori.kemdikbud.go.id/1230/1/Baha n\%20belajar\%20perca\%20lengkap-w.pdf

https://club.iyaa.com/bbs/board.php?bo_table= DIY\&wr id=157

\section{DOKUMENTASI KEGIATAN}
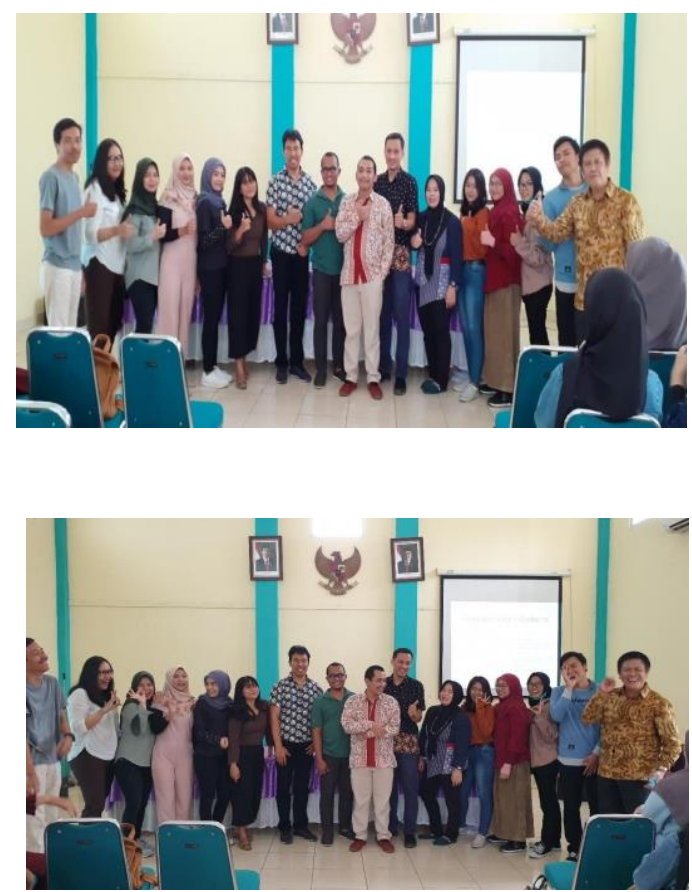